\title{
Polyvinylimidazole-wrapped Halloysite Nanotubes for High Proton Conductivity in Polymer Electrolyte Membranes
}

\author{
Xiaoyang Liu ${ }^{1}$, Xiang Sun, Hongqian Ren, Mengjie Yang, Mingling Xia, Jinghe Hou*, Yi Feng*, \\ Huili Ding ${ }^{*}$ \\ Institute of Polymer Science and Engineering, School of Chemical Engineering and Technology, \\ Hebei University of Technology, Tianjin 300130, PR China \\ *E-mail: aleeding@hebut.edu.cn, 741925221@qq.com, yvonne.f512@gmail.com
}

doi: $10.20964 / 2020.10 .71$

Received: 20 December 2019 / Accepted: 6 August 2020 / Published: 31 August 2020

The construction of continuous proton transfer channels within a proton exchange membrane is an important and challenging task for the logical design of proton exchange membranes. Herein, inspired by the mechanism of moisture transport used by plants and biological proton transfer, polyvinylimidazole-wrapped halloysite nanotubes were proposed as proton carriers and nanochannels to afford polymer electrolyte membranes with high proton conductivities. The composite membranes were constructed by mixing sulfonated poly(aryl ether sulfone) (SPES) matrix and polyvinylimidazolewrapped halloysite nanotubes (PVI@HNTs), PVI@HNTs were prepared by distillation-precipitation polymerization among them. Through a comprehensive study on the microstructure, physical and chemical properties and proton conductivity of the composite membrane, it was found that welldispersed PVI @HNTs improved the mechanical and thermal stability of the nanocomposite membrane. The sulfonic acid groups in the polymer matrix formed acid-base pairs with the imidazolyl groups of the PVI@HNTs, which formed proton hopping pathways and nanochannels with low energy barriers for proton transfer. In addition, similar to plant ducts, one-dimensional and large aspect ratio tubular structures provided rapid transport channels for moisture in the membrane. The combination of "vehicle mechanism" and "Grotes mechanism" has significantly improved the proton conductivity of the SPES / PVI @ HNTs-X composite membrane. Specifically, the proton conductivity of $0.198 \mathrm{~S} \mathrm{~cm}^{-1}$ at $80^{\circ} \mathrm{C}$ was obtained for SPES/PVI@HNTs-7.5 membrane, which was $46 \%$ higher than that of SPES. This research could provide a general and simple strategy to design composite exchange membranes.

Keywords: Halloysite nanotubes, nanocomposite membranes, proton transport channels, polyvinylimidazole-wrapped halloysite nanotubes, proton exchange membrane

\section{$\underline{\text { FULL TEXT }}$}


(C) 2020 The Authors. Published by ESG (www.electrochemsci.org). This article is an open access article distributed under the terms and conditions of the Creative Commons Attribution license (http://creativecommons.org/licenses/by/4.0/). 